\title{
Synthesis, characterization and functional evaluation of gold nanoparticles prepared using Dovyalis abyssinica leaf extracts as reducing and surface capping agent
}

\author{
Abera Beyene Gebresilassie ${ }^{1}$ and Adam Mekonnen Engida ${ }^{1,{ }^{*}}$ \\ Department of Industrial Chemistry, Nanotechnology Center of Excellence, Addis \\ Ababa Science and Technology University, Addis Ababa, Ethiopia
}

\begin{abstract}
Green synthesis of nanoparticles using plants and microorganisms is biologically safe, cost effective, and environmentally friendly technology. Gold nanoparticles (Au NPs) were synthesized using aqueous extracts of leaves of Dovyalis abyssinica as reducing and surface capping agent and the catalytic activity, antibacterial action and antioxidant potential of the synthesized AU NPs were evaluated. Firstly, $\mathrm{HAuCl}_{4}$ was synthesized in the laboratory from metallic gold and hydrochloric acid using a predesigned method. Secondly, Au NPs was synthesized by mixing $\mathrm{HAuCl}_{4}$ and the plant extract at $45^{\circ} \mathrm{C}$ with a digestion time of $1 \mathrm{~h}$. The size of the nanoparticles was modulated by varying the ratio of the plant extract and $\mathrm{HAuCl}_{4}$ with known concentrations. The synthesized Au NPs showed strong absorption around $540 \mathrm{~nm}$ which lies in the characteristic absorption region of Au metal nanoparticles (520-580 $\mathrm{nm})$. The X-ray diffraction spectrum of the synthesized Au NPs showed characteristic crystalline structures of gold. The scanning electron spectroscopy images of the synthesized $\mathrm{Au}$ NPS revealed the presence of mixed shapes predominantly of irregular shapes and a particle size analyzer displayed an average size of $63.13 \mathrm{~nm}$. The fourier-transform infrared spectrum of Au NPS confirmed the presence of amine, carbonyl and hydroxyl functional groups as surface capping molecules. Although the synthesized $\mathrm{Au}$ NPs showed poor bacterial growth inhibition activity on two selected bacteria, it demonstrated excellent free radical scavenging activity against 2, 2Diphenyl-2-picrylhydrazyl (DPPH) radical and good catalytic activity for degrading bromothymol blue and methyl red compounds. In contrast to the hexane and ethyl acetate extracts, the aqueous fraction was identified as powerful reducing fraction for the synthesis of Au NPs in this experiment.
\end{abstract}

Keyword: Green synthesis; Dovyalis abyssinica; Nanoparticles; Antioxidant; Catalyst; Antibacteria.

DOI: https://dx.doi.org/10.4314/ejst.v14i2.6

* Corresponding author: adam.mekonnen@aastu.edu.et

(C) This is an Open Access article distributed under the terms of the Creative Commons Attribution License (http://creativecommons.org/licenses/CC BY4.0) 


\section{INTRODUCTION}

Synthesizing metal nanoparticles using microorganisms and plants has been extensively studied and been recognized as a green and efficient technology (Singh et al., 2016). In recent years, several reports suggested the focus on greener approach for the synthesis of nanoparticles (Jyoti and Singh, 2016; Fransis et al., 2018) using biological methods. Currently, different plant parts (root, fruit, peel, stem, flower and leaf) are being used for green synthesis of gold nanoparticles (Au NPNs) including: flower extract of Plumeria alba (Mata et al., 2016), fruit extract of Piper longum (Nakkala et al., 2016), leaf extracts of Terminalia arjuna (Dudhane et al., 2019), leaf extract of Ziziphus zizyphus (Aljabali et al., 2018), leaf extract of Indigofera tinctoria (Vijayan et al., 2017) and leaf extract of Acer pentapomicum (Khan et al., 2018).

To date, natural resources are exploited and biological synthesis routes of metal nanoparticles implemented with proven advantages. There are environmentally friendly, feasible to scale up and cost effective. The biological method of synthesis (of nanoparticles) can produce stable nanoparticles with controlled size and shape, avoids complex chemical reagents and toxic contaminants and uses available medicinal plants and microorganisms (Singh et al., 2016)

D. abyssinica, whose leaves are used as a household remedy against various human ailments, grows widely in Ethiopia. Its leaves serve as fodder for livestock, primarily for goats and sheep, serves as live fence, and the flowers attract foraging bees. The crude methanol and dichloromethane leaf extracts of $D$. abyssinica are reported to possess important active biomolecules such as phenolics, alkanoids, tannins, sapponins, steroids, sterols and terpenes. Crude dichloromethane and methanol leaf extracts of $D$. abyssinica are reported as anti-trypanosomal agent that may lead for the development of effective alternative anti-trypanosomal drugs (Belay Tadesse et al., 2015). This plant can be exploited as source of biomolcules to synthesis metal nanoparticles, which is economical and environmentally and socially acceptable.

To the best of our knowledge, there is no known research report on the synthesis of metal nanoparticles by using bioactive molecules from D. abyssinica as a reducing agent of metal ions. In this experiment, water extract of $D$. abyssinica leaf was used as reducing and stabilizing agent to synthesis Au NPs. The Au NPs are synthesized using predesigned green process and the synthesized $\mathrm{Au}$ NPs were characterized using multiple analytical techniques: UV-Vis spectrophotometer (UV -Vis), particle size 
analyzer, scanning electron microscope (SEM), X-Ray diffraction (XRD) and Fourir transform infrared (FTIR). effect of concentration of metal ions and concentration of leaf extract were evaluated to optimize a process to synthesis possibly small size Au NPs. The catalytic activity and antioxidant activities of the synthesized Au NPs was promising but, the antibacterial activity of the new Au NPs was poor. The reducing potentials of hexane, ethyl acetate and aqueous fractions showed a correlation of polarity of compounds with their reducing potential.

\section{MATERIALS AND METHODS}

\section{Chemicals and instruments}

Hexane (95\%, lab grade; Nutan Chemicals), ethyl acetate (99.5\%, Alpha Chemica), bacteriological media (BD), Hydrochloric acid (36\%, Loba Chemie), acetic anhydride (70\%, Taj Pharmaceutical limited), 2,2-Diphenyl2-picrylhydrazyl (95\%; Sisco Research Laboratory)), Methyl red (solution $0.025 \%$; Fisher chemical), Ascorbic acid (98\%, P J Chemicals), potassium permanganate $\left(\mathrm{KMnO}_{4}\right)(98 \%$, Libox Chem India Pvt. Ltd.), Sulphuric acid (98\%; PVS Chemicals Inc.), Gentamicin (2 mL: $160 \mathrm{mg}$, Sundent pharmaceutical Co., Ltd.), Sodium hydroxide (laboratory grade, Fisher Scientific), Ferric chloride (Laboratory grade, anhydrous powder, Fisher Scientific), Bromotyhamol blue (98\%, Alpha Chemica), potassium ferrocyanate $\left(\mathrm{K}_{4} \mathrm{Fe}(\mathrm{CN})_{6}\right) \quad(99 \%$, Hindusthan Chemicals Company) and distilled water were used during the experiment. Analytical instruments: Freeze dryer (LFZ/EV), SEM (Inspect F50), X-ray Diffraction (BTX-528), FTIR (Thermo Scientific iS50 ABX), Zetasizer nano (Malvern, ZE3600) and Ultra violet-Visible spectrophotometer (Jasco, V-770) were used.

\section{Experimental methods}

\section{Collection and identification of the plant material}

The leave of D. abyssinica was collected from Bishoftu town (Ethiopia). The freshly collected leaves were washed thoroughly with tap-water to remove any adsorbed impurities. Next it was dried in open air in the shade for one week and then it ground by blender and packed in polyethylene bags to minimize material exchange with the surrounding and stored in refrigerator to control any biological and chemical activities.

\section{Extraction}


Bioactive compounds were extracted from $D$. abyssinica using a simple procedure as follows: $10 \mathrm{~g}$ of leaf powder was mixed with $100 \mathrm{~mL}$ distilled water in a round bottom flask and the mixture was agitated using magnetic stirrer at $65^{\circ} \mathrm{C}$ for $4 \mathrm{~h}$. The content was allowed to cool to room temperature and filtered through Whatman filter paper No1 to obtain a clear extract. Then the filtrate was dried using freeze drying and the percentage yield of the crude dry extract was determined using the following equation.

$$
\mathrm{Y}_{\text {extract }}(\%)=\left(\frac{M \text { extract }}{\text { Mfeed }}\right) \times 100 \%
$$

Where $Y_{\text {extract }}$ is the extract yield, $M_{\text {extract }}$ is the dry extract mass $(\mathrm{g})$ and $\mathrm{M}_{\text {feed }}$ is the feed mass $(\mathrm{g})$.

This experiment was done in triplicate and the average percentage yield was calculated accordingly. Finally, the dry extract was stored for later experiments.

\section{Chemical composition of the aqueous extract of leaves}

The composition of $D$. abyssinica crude extract was evaluated to determine the chemical constituents. The phytochemical nature of the extract was evaluated for a set of bioactive compounds: alkanoids, flavonoids, phenolics, saponins, steroids, tannins and terpenes using pre-established methods for each group of compounds (Malathi et al., 2018).

To evaluate water extracts of $D$. abyssinica for saponins, $0.5 \mathrm{~g}$ of the dry extract was added in a test tube with $10 \mathrm{~mL}$ of distilled water. The test tube was shaken vigorously for $30 \mathrm{~s}$ and allowed to stand in a vertical position and kept for $30 \mathrm{~min}$. The formation of foam on the surface of the test solution confirmed the presence of saponins. Similarly, presence of tannins in the sample was evaluated using $2 \mathrm{~mL}(5 \mathrm{mg} / \mathrm{mL})$ of it in $10 \mathrm{~mL}$ test tube. Then 3 drops of $10 \%$ ferric chloride were added to study characteristic properties of tannins.

To test for flavonoids, $1 \mathrm{~mL}$ of the test solution was placed in test tube and 3 $\mathrm{mL}$ of $10 \%$ sodium hydroxide was added followed by $3 \mathrm{~mL}$ of $10 \% \mathrm{HCl}$ to study the response of flavonoids for acids and bases.

To evaluate for steroids, $1 \mathrm{~mL}$ of extract was added in a test tube with drops of acetic anhydride. Then concentrated $\mathrm{H}_{2} \mathrm{SO}_{4}$ was carefully added to the side of the test tube to observe the formation of a characteristic brown ring at the boundary of the mixture. 
To evaluate phenolics, $2 \mathrm{~mL}$ of extract was added in a test tube, then $1 \mathrm{~mL}$ of $1 \%$ ferric chloride $\left(\mathrm{FeCl}_{3}\right)$ and $1 \mathrm{~mL}$ of $\mathrm{K}_{4} \mathrm{Fe}(\mathrm{CN})_{6}$ to check the formation of bluish green color.

Mayer's test (potassium mercury iodide solution in water) was used to test alkaloids qualitatively as follows: a few drops of the Mayer's reagent were added to $2 \mathrm{mg}$ of plant extract to study the formation of white or pale-yellow precipitate for alkaloids.

A test for triterpenoids and terpenes, $1 \mathrm{~mL}$ of test solution was dissolved in an acetic anhydride and heated to boiling and then cooled. Then $1 \mathrm{~mL}$ concentrated $\mathrm{H}_{2} \mathrm{SO}_{4}$ was added on sides of the inclined test tube and left for 1 $\mathrm{h}$ to monitor the formation of brown/pink ring at the interface for presence of nitrate ion in the test solution.

\section{Synthesis of $\mathrm{HAuCl}_{4}$}

$\mathrm{HAuCl}_{4}$ was synthesized in the laboratory following King et al. (2015) procedure. To do this, $14 \mathrm{~mL}$ hydrochloric acid was placed in a pressureequalizing dropping funnel, and slowly added drop-wise to a side-arm flask containing potassium permanganate $(3.0 \mathrm{~g})$. Then the resulting chlorine gas was allowed to pass into a two-neck round-bottom flask containing $100 \mathrm{~mL}$ double distilled water and $100 \mathrm{mg}$ of pure gold. The excess (unreacted) chlorine gas was bubbled through a solution of sodium thiosulfate $(1.1 \mathrm{~g})$ in $50 \mathrm{~mL}$ of water. The reaction mixture in two-neck round-bottom flask was agitated with a magnetic stirrer at $45{ }^{\circ} \mathrm{C}$ until all the reaction was completed.

\section{Synthesis and size optimization of Au NPs}

Au NPs was synthesized following previous methods (Aljabali et al., 2018; Kato et al., 2019) with slight modification. Mixtures of $5 \mathrm{~mL}$ of $5.2 \mathrm{mM}$ $\mathrm{HAuCl}_{4}$ and $5 \mathrm{~mL}(1 \mathrm{mg} / \mathrm{mL})$ leaf extract of $D$. abyssinica was incubated at $45{ }^{\circ} \mathrm{C}$ and the progress of the reaction was routinely monitored by observing colour change as of Gandhi et al. (2019). In this experiment, the intensity of the colour of the solution had got almost constant after $1 \mathrm{~h}$ observation. At the end of the reaction time, the Au Nps were collected by centrifugation at 2000 rpm for $15 \mathrm{~min}$. The pellet obtained was washed three times by deionized water and then air dried. The synthesized Au NPs were suspended in distilled water and analyzed using UV-Vis spectrometer to study the characteristic absorption band. 
The size of the nanoparticles was modulated by varying the ratio of the metal salt $\left(\mathrm{HAuCl}_{4}\right)$ and the D. abyssinica leaf extract solutions with given concentrations of $1 \mathrm{mg} / \mathrm{mL}$ leaf extract and $5.2 \mathrm{mM} \mathrm{HAuCl}_{4}$ solution by varying volume ratio $(\mathrm{V}: \mathrm{V} ; 1: 9,1: 4,3: 7,2: 3,1: 1,3: 2,7: 3,4: 1,9: 1)$. Then mixtures were heated at $45{ }^{\circ} \mathrm{C}$ for $1 \mathrm{~h}$ with magnetic stirring and then the synthesized $\mathrm{Au}$ NPs from each mixture was collected and cleaned for further analysis.

\section{Characterization of Au NPs}

Different characterization techniques were used: UV-Vis spectrometer to monitor reaction process; SEM to study surface morphology and particle shape; XRD to study characteristic crystal structure; particle size analyzer to determine the average particle size; and FT-IR to determine the chemical nature of surface capping molecules of the Au NPs.

\section{Antibacterial, catalytic and antioxidant activities of Au NPs}

\section{Antibacterial activity}

The anti-bacterial activity of the synthesized Au NPs was evaluated against two selected human pathogens: the gram-negative Escherichia coli (E. coil) and the gram-positive bacteria Staphylococcus aureus, using the agar well diffusion method as of Dudhane et al. (2019) and Francis et al. (2019) with slight modification. Growth media (Muller-Hinton agar plates) were swabbed with E. coil and Staphylococcus aureus. Then sterile paper discs with $4 \mathrm{~mm}$ diameter were placed on the swabbed plates. Then the papers were loaded with $(50 \mu \mathrm{L})$ of different concentrations of leaf extract and $\mathrm{Au}$ NPs. Different concentrations of leaf extract $(0.5 \mathrm{mg} / \mathrm{ml}, 0.75 \mathrm{mg} / \mathrm{mL})$ and Au NPs $(0.25 \mathrm{mg} / 100 \mathrm{~mL}$ and $0.50 \mathrm{mg} / 100 \mathrm{~mL})$ were prepared separately. A standard antibiotic solution (Gentamicin, $0.25 \mathrm{mg} / \mathrm{mL}$ ) was used as a standard for reference. The plates were incubated at $37{ }^{\circ} \mathrm{C}$ for $24 \mathrm{~h}$ and the zone of inhibition $(\mathrm{mm})$ was captured and inspected.

\section{Catalytic activity}

The catalytic degrading activity of the synthesized Au NPs was evaluated on two different organic dyes: Methyl red and bromothyamol blue as follows: 1 $\mathrm{mg}$ of each dye was diluted with $100 \mathrm{~mL}$ of distilled water and $50 \mathrm{~mL}$ of each dye solution was mixed with $2 \mathrm{~mL}$ of $5.2 \mathrm{mM}$ Au NPs. Then mixtures of each test solution were digested for $1 \mathrm{~h}$ and in the mean time: $3 \mathrm{~mL}$ of each digest were taken in every $15 \mathrm{~min}$ interval $(0,15,30,45$, and $60 \mathrm{~min})$ 
and scanned from 200 to $800 \mathrm{~nm}$ using Uv-Vis spectrophotometer to study the progress of degradation.

\section{Antioxidant activity}

The radical scavenging assay of the synthesized Au NPs was performed using DPPH radical following previous procedures (Francis et al., 2018; Patil et al., 2019) with slight modification. Both the D. abissinica leaf extract and Au NPs were examined separately to study the chemical nature of bioactive compounds extracted from the plant and the synthesized Au NPs capped with extracted molecules. The test solutions of Au NPs and D. abissinica extract were prepared separately from stock solutions with different concentrations $(10,20,30,40$, and $50 \mu \mathrm{g} / \mathrm{mL})$ in ethanol. Ascorbic acid was used as standard antioxidant. Next, $4 \mathrm{~mL}$ of $0.07 \mathrm{mM}$ DPPH (in ethanol) was added to $1 \mathrm{~mL}$ of each test solution of Au NPs, leaf extract, ascorbic acid solutions and to the blank (ethanol was used as a blank). Then reaction mixtures were incubated in the dark for $30 \mathrm{~min}$ (at room temperature). After completion of incubation, the supernatant solution of each concentration, including the blank solution, were analyzed by UV-Vis spectrophotometer at $517 \mathrm{~nm}$.

\section{Effect of polarity on reducing potential}

There is no a single research report regarding to the effect of polarity of extracted compounds on reduction of metal ions during nanoparticle synthesis. Hence, fractions of the crude extract were evaluated to study the effect of polarity on reduction of $\mathrm{Au}^{3+}$ as follows: the water extract of $\mathrm{D}$. abyssinica leaf was fractionated using hexane followed by ethyl acetate sequentially and the remaining aqueous layer was taken as an aqueous fraction. The solvents; hexane and ethyl acetate were evaporated from the respected fractions and re-dissolved in distilled water. Then, fractions were used as a reducing medium for the synthesis of Au NPs under previously established conditions.

\section{RESULTS AND DISCUSSION}

\section{Phytochemicals in aqueous extract of leaves}

From triplicate extractions, the average dry extract was found to be $12.56 \%$ from dry mass. The water extract of D. abyssinica was phytochemically evaluated to determine the chemical constituents: alkanoids, flavonoids, 
phenolics, saponins, steroids, tannins and terpenes present in the plant leaf (Table 1).

The presence of saponins was confirmed with formation of foam on the surface. This is because saponin molecules align themselves vertically on the surface with their hydrophobic orientation away from water (Malathi et al., 2018). The test for tannins in D. abyssinica extract showed a positive result and this was confirmed by the formation of the bluish black color with addition of ferric chloride to the sample extract. The confirming color is developed due to the formation of a complex as result of reaction of tannins with ferric chloride. The presence of steroids was confirmed with formation of a brown ring as result of the formation of trienones. The presence of phenolics was confirmed by the observed bluish green color which was a positive confirmation for formation of ferric phenolate salt as a precipitate. The absence of pale-yellow precipitate confirmed the absence of alkaloids in the plant extract. And the presence of terpenes was confirmed by the formation of brown ring at the interface on addition of $1 \mathrm{~mL}$ concentrated $\mathrm{H}_{2} \mathrm{SO}_{4}$ in $1 \mathrm{~mL}$ of test solution dissolved in an acetic anhydride heated to boiling followed by cooling. Among the evaluated bioactive compounds alkaloids and flavonoids were not detected.

Table 1. Phytochemical test results of D. abyssinica leaf extract.

\begin{tabular}{ll}
\hline Water extracted leaves & Result \\
\hline Akaloids & - \\
Tannins & + \\
Flavonoids & - \\
Phenolic compounds & + \\
Steroids & + \\
Terpenes & + \\
Saponins & + \\
\hline
\end{tabular}

\section{Synthesis of $\mathrm{HAuCl}_{4}$}

The oxidation of gold metal to form aqueous solutions of gold (III) chloride was successfully achieved through introduction of chlorine gas to water containing the gold. The formation of yellowish color (Figure 1) was observed which corroborated previous reports (Shirin et al., 2015). The reaction was quantitative and no manganese-containing by-products were detected, which may have arisen from the chlorine production process. Thus, the concentration of the gold (III) chloride solutions was reasonably calculated from the mass of the gold metal and the final volume of water. The final volume of the solution was $97.24 \mathrm{~mL}$ and the concentration of $\mathrm{Au}^{3+}$ was calculated by dividing the mass of pure gold by the volume of the final solution $(97.24 \mathrm{~mL})$ and was found to be $1.03 \mathrm{mg} / \mathrm{mL}(5.2 \mathrm{mM})$ in the 
synthesized solution. This solution was taken as a stock solution for next experiments.
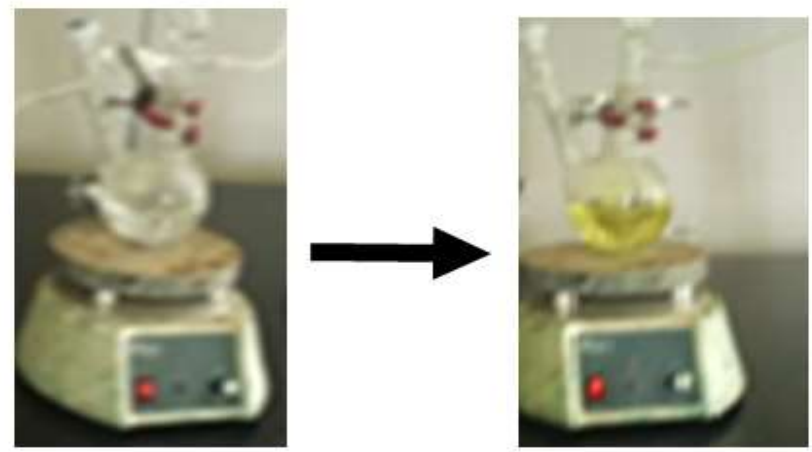

Figure 1. Colour change during the synthesis of $\mathrm{HAuCl}_{4}$.

\section{Synthesis and characterization of Au NPs}

\section{Synthesis of Au NPs}

Synthesis of Au NPs by $D$. abyssinica leaf extract was formed after the extract was incubated with $\mathrm{HAuCl}_{4}$ solution. First, the synthesis of the nanoparticle was confirmed by visual observation with the appearance of colour change in the reaction medium. During the synthesis of Au NPs, the color of the medium turned deep pink due to the excitation of surface plasmon vibration which indicates the formation of Au NPs. The result was consistent with previous reports (Singh et al., 2016).

The aqueous solution of Au NPs was scanned by UV-Vis spectrometer in the range of 460-760 nm as of Aljabali et al. (2018) and Vijayan et al. (2018) to check the presence of characteristic absorption band of $\mathrm{Au}$ metal nanoparticles from UV-Vis spectrum. The synthesis of Au NPs was confirmed by the observed absorption maxima around $540 \mathrm{~nm}$.

\section{Characterization of Au NPs}

\section{UV-Vis analysis}

The nanoparticle with the smallest size is effective for most of applications due to greater surface area to volume ratio (Chandran et al., 2017). Hence it was important to investigate the optimum concentration of reactants on size of Au NPs. The position of strong absorption corresponds to the size whereas the intensity of the absorption refers to the concentration of the synthesized 
$\mathrm{Au}$ NPs. The effect of concentration on particle size was obtained by varying volume ratios of reactants $(\mathrm{V}: \mathrm{V} ; 1: 9,1: 4,3: 7,2: 3,1: 1,3: 2,7: 3,4: 1$, and 9:1) as shown in Figure 2. The Au NPs from 1:1 ratio showed absorption maxima at the shortest wavelength indicating the smallest nanoparticle. Hence, the smallest size Au NPs was obtained from 1:1 volume ratio of leaf extract (1 $\mathrm{mg} / \mathrm{ml}$ ) and $2 \mathrm{mM} \mathrm{HAuCl}$. This result was in line with previous reports (Aljabali et al., 2018).

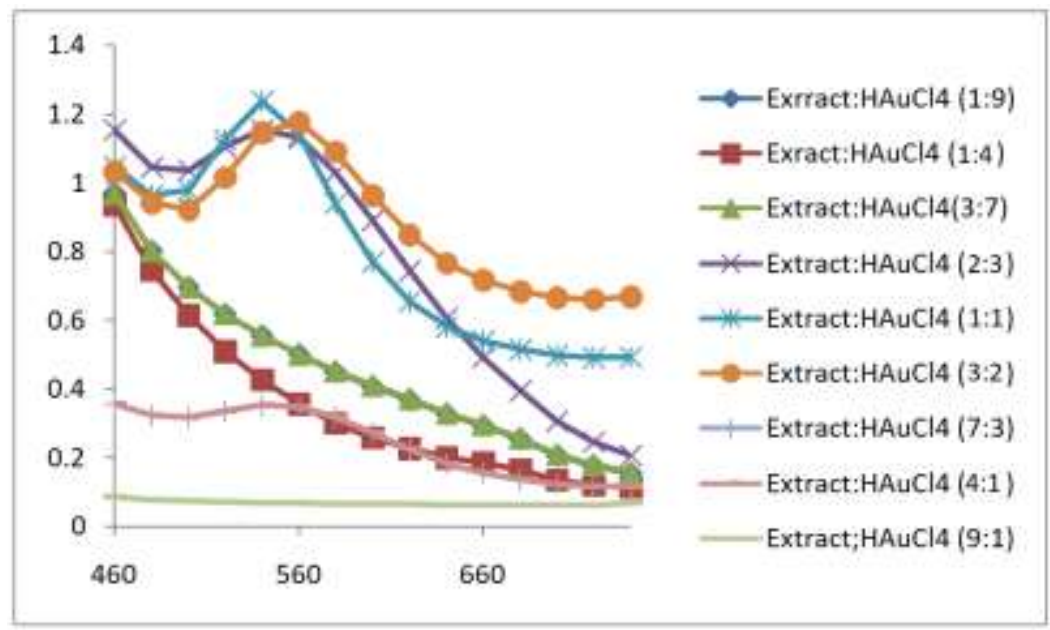

Figure 2. UV-Vis spectra of synthesized Au NPs from 9 ratios of extract: $\mathrm{HAuCl}_{4}$.

Particle size analysis

The synthesized Au NPs from different volume ratios of reactants $(\mathrm{V}: \mathrm{V} ; 1: 9$, $1: 4,3: 7,2: 3,1: 1,3: 2,7: 3,4: 1$ and 9:1) was analyzed using particle size analyzer and the average size was ranged from 63.13 to $1000 \mathrm{~nm}$ in the range of all ratios as shown in Figure 3. The smallest particle size of Au NPs was found with the ratio of 1:1 which is consistent with Figure 2. As the ratio of (plant extract: $\mathrm{HAuCl}_{4}$ ) varied from 1:9 to $1: 4$, the particle size increased from 102.6 to $199.5 \mathrm{~nm}$. When the concentration of $\mathrm{HAuCl}_{4}$ in the ratio decreased from 1:4 to $3: 7$ the average particle size decreased abruptly to $63.78 \mathrm{~nm}$ but, there was little size difference $(63.30-63.65 \mathrm{~nm})$ as the ratio varied from $3: 7$ to $3: 2$.

However, when the mixture ratio changed from $3: 2$ to $7: 3$ the particle size suddenly increased to $200 \mathrm{~nm}$ and the size of the synthesized Au NPs was consistently increased from $200-504.8 \mathrm{~nm}$ when the volume ratio of 
reactants varied from 3:2 to 9:1. This result was consistent with the previously reported information by Anigol et al. (2017). Based on this outcome, it could be concluded that the concentration had significant effect on the size of nanoparticles. The smallest average particle size (63.13) was obtained from the volume ratio of 1:1 and it was considered as the optimum concentration combination of reactants for this experiment (Table 2).
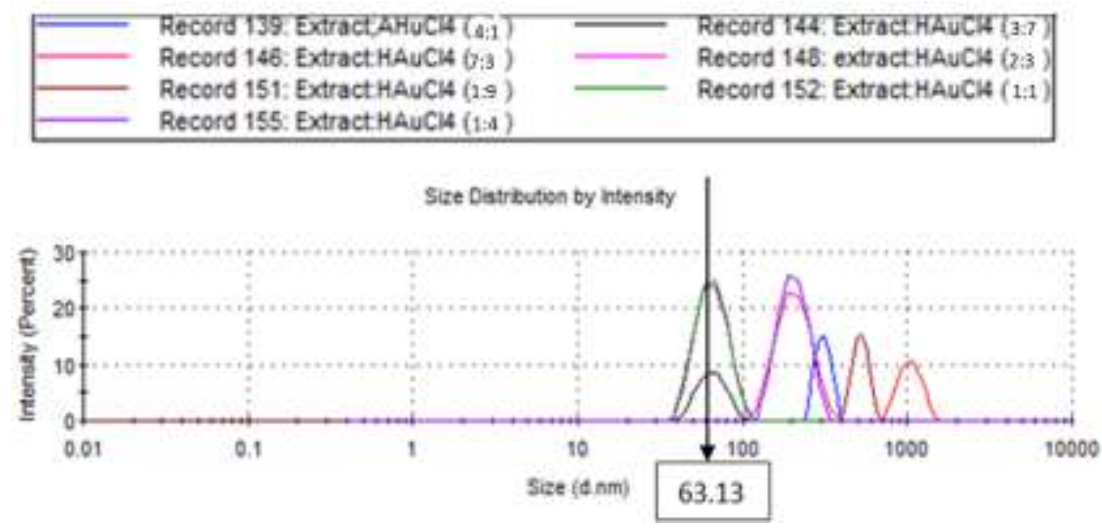

Figure 3. Average sizes of synthesized Au NPs from different ratios of plant extract and $\mathrm{HAuCl}_{4}$.

Table 2. Average particle size summary for synthesized Au NPs from different ratios of reactants (Plant extract: $\mathrm{HAuCl}_{4}$ ).

\begin{tabular}{lccccccccc}
\hline $\begin{array}{l}\text { Plant extract: } \\
\mathbf{H A u C l}_{\mathbf{4}} \text { (V/V) }\end{array}$ & $\mathbf{1 : 9}$ & $\mathbf{1 : 4}$ & $\mathbf{3 : 7}$ & $\begin{array}{r}\mathbf{2 :} \\
\mathbf{3}\end{array}$ & $\mathbf{1 : 1}$ & $\mathbf{3 : 2}$ & $\mathbf{7 : 3}$ & $\mathbf{4 : 1}$ & $\mathbf{9 : 1}$ \\
\hline Average size (d, nm) & 102.6 & 199.5 & 63.78 & 63.3 & 63.1 & 63.7 & 200 & 302 & $\begin{array}{c}504 . \\
\end{array}$ \\
\hline
\end{tabular}

\section{FT-IR analysis}

FTIR analysis was performed to identify the nature of compounds in $D$. abyssinica leaves which are responsible for the reduction, capping and stabilization of the Au NPs. FTIR spectrum revealed the presence of different functional groups (Figure 4). The FTIR peaks observed at $3856.38 \mathrm{~cm}^{-1}$ stands for the bond between $\mathrm{OH}$ with Au. The double peaks at $3732.42 \mathrm{~cm}^{-1}$ and $3608.48 \mathrm{~cm}^{-1}$ stand for stretching energy of $\mathrm{H}-\mathrm{N}$ in primary amines on the surface of Au NPs. The band at $2344.45 \mathrm{~cm}^{-1}$ stands to the absorption band of carbon dioxide attached to the surface of Au NPs. The absorption peak at $1522.84 \mathrm{~cm}^{-1}$ indicates the stretching of $\mathrm{C}=\mathrm{O}$ which chelates $\mathrm{Au}$ metals. The observed peak at $1034.47 \mathrm{~cm}^{-1}$ shows the aliphatic $\mathrm{C}-\mathrm{N}$ structure of the protein and $\mathrm{C}-\mathrm{O}$ bonds. Thus, based on the information obtained from 
FTIR spectrum it could be assumed that $\mathrm{C}=\mathrm{O}, \mathrm{C}-\mathrm{N}$ and $\mathrm{OH}$ are functional groups that could be involved in the reduction process during the synthesis of $\mathrm{Au}$ NPs.

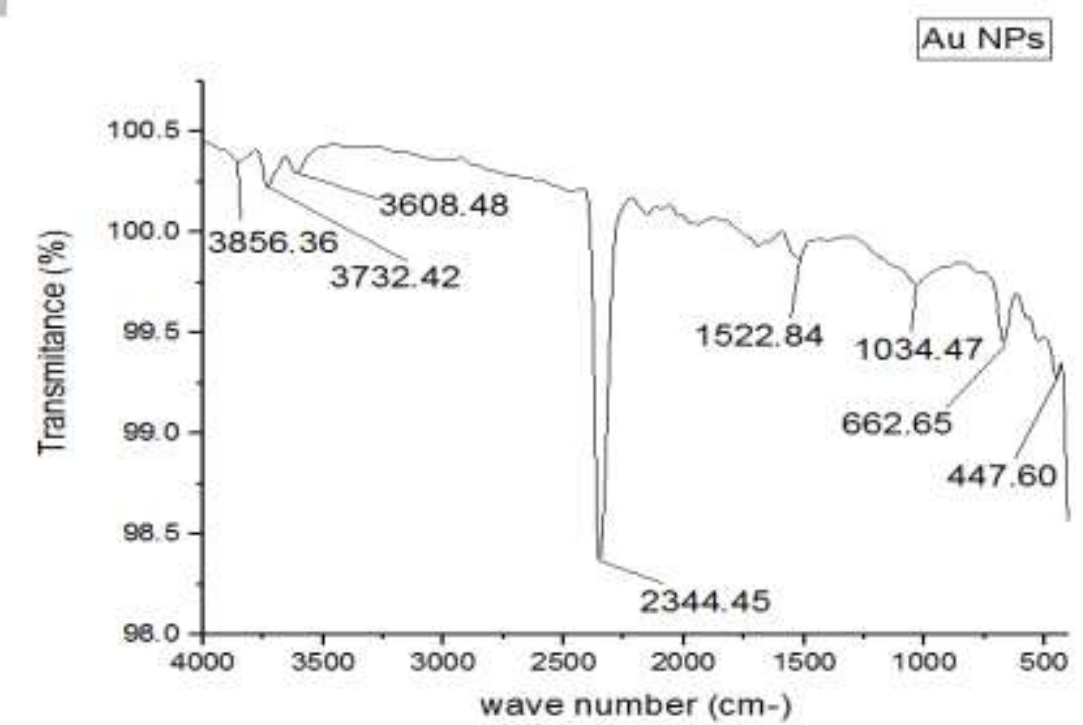

Figure 4. FTIR spectra of Au NPs.

\section{XRD analysis}

X-ray diffraction analysis was carried out to study the characteristic crystalline nature of the synthesized Au NPs. The XRD analysis of Au NPs illustrate four characteristic diffraction peaks at $38.19^{\circ}, 44.46^{\circ}, 64.60^{\circ}, 77.75^{\circ}$, which could be indexed to (111), (200), (220), and (311) peaks representing characteristic diffraction of elemental $\mathrm{Au}^{\circ}$, which confirmed the formation of crystalline Au NPs (Figure 5). The broad peak between $50^{\circ}$ and $60^{\circ}$ with fine peaks might be assigned to impurities like halites originated from metallic gold which was used to synthesize $\mathrm{HAuCl}_{4}$. This result was consistent with previously reported result by Biao et al. (2018).

\section{SEM analysis}

The images obtained from the SEM analysis showed nanoparticles with predominantly of irregular shapes and some rod like structures with a range of sizes (Figure 6). There were also very small nanoparticles agglomerated with the matrix. 


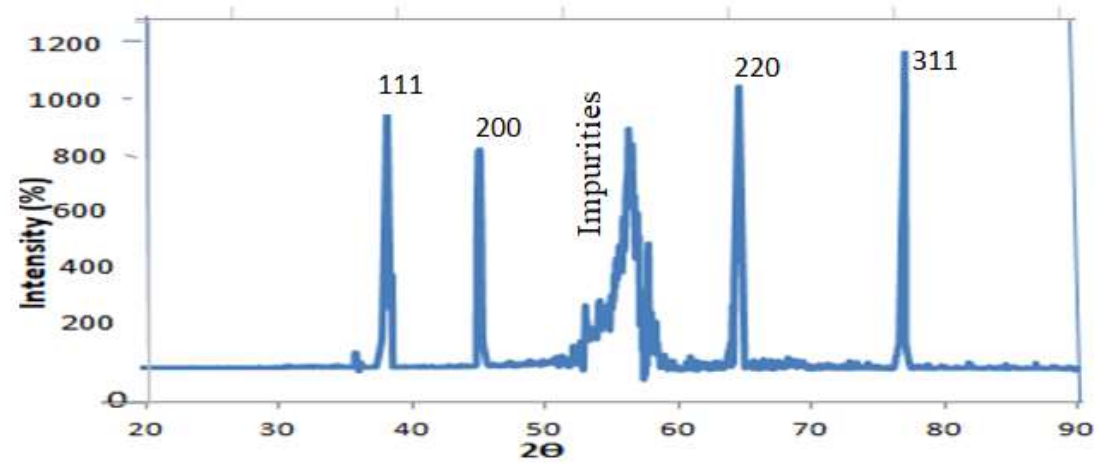

Figure 5. XRD spectra of Au NPs.

\section{Antibacterial, catalytic and antioxidant activities of Au NPs}

\section{Anti-bacterial activity of Au NPs}

The antibacterial assays of the synthesized Au NPs and the leaf extract were done against gram negative E. coil and gram-positive Staphylococcus aureus bacteria using gentamicin as reference. The antibacterial activities of both $\mathrm{Au}$ NPs and the leaf extract did not show growth inhibition on both Staphylococcus aureus and E. coil bacteria (Figure 7).

Different concentrations of AU NPs were also evaluated to study the effect of concentration on bacterial growth inhibition; however, the result was concentration independent. This can be justified by the nature of surface capping molecules from $D$. abyssinica extract. However, previously reported gold nanoparticles which were synthesized using Mussaenda glabrata leaf extract were reported as effective anti-bacterial agent on different human pathogenic bacteria (Francis et al., 2017). Different concentrations of AU NPs were also evaluated to study the effect of concentration on bacterial growth inhibition; however, the result was concentration independent. This can be justified by the nature of surface capping molecules from $D$. abyssinica extract. However, previously reported gold nanoparticles which were synthesized using Mussaenda glabrata leaf extract were reported as effective anti-bacterial agent on different human pathogenic bacteria (Francis et al., 2017). 


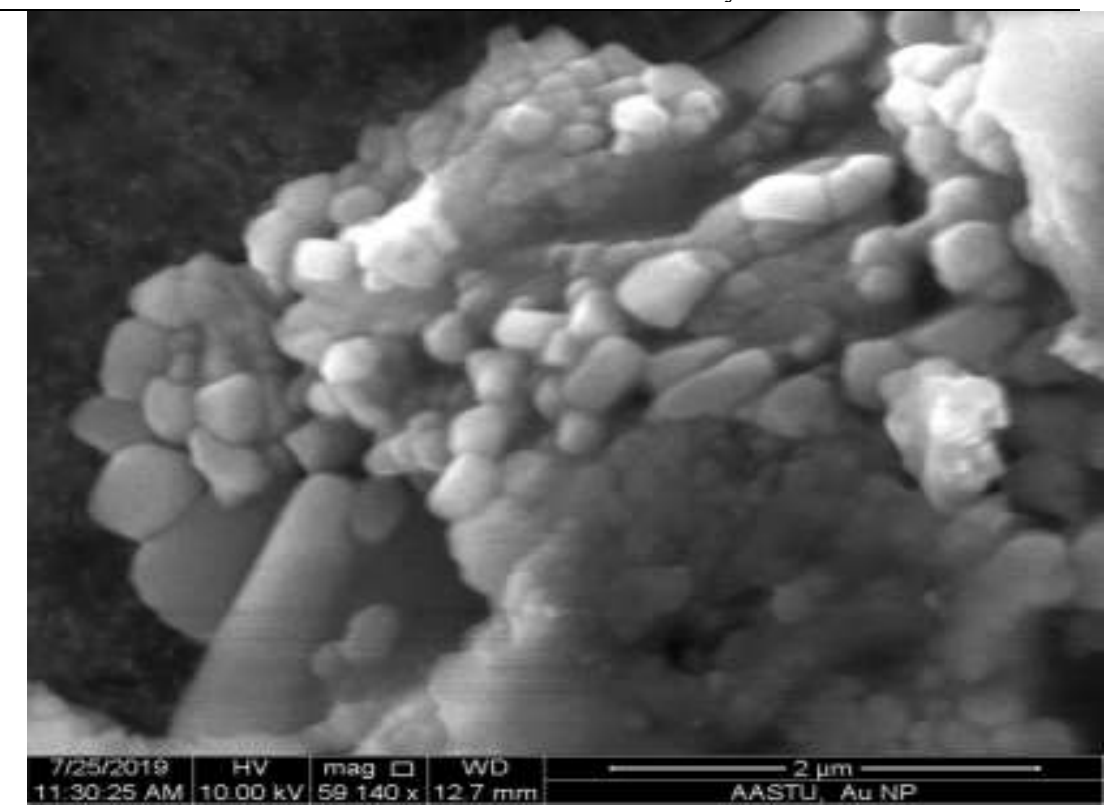

Figure 6. SEM images of synthesized Au NPs.

Similarly, Au NPs with size of 5-12 nm were reported as efficient growth inhibitor of gram positive Sthaphylococus aureus and gram-negative E. coli (Srinath et al., 2017). Yet, the nature of surface capping molecules was not studied, which might contain organic compounds having antibacterial agent (Francis et al., 2017; Srinath et al., 2017). Although the mechanism of action how nanoparticles affect bacterial growth need to be determined, the poor antibacterial activity of the newly synthesized Au NPs might be justified by the size and shape of $\mathrm{Au}$ NPs or by the nature of the surface capping molecules originated from the plant extract.

\section{Catalytic activity}

To study the catalytic activity of newly synthesized Au NPs, two organic compounds, methyl red and bromothyamol blue were considered. The catalytic activity of $\mathrm{Au}$ NPs on methyl red and bromothyamol blue was evaluated using UV-Vis spectrophotometer by scanning the digested solutions from 200 to $800 \mathrm{~nm}$. 

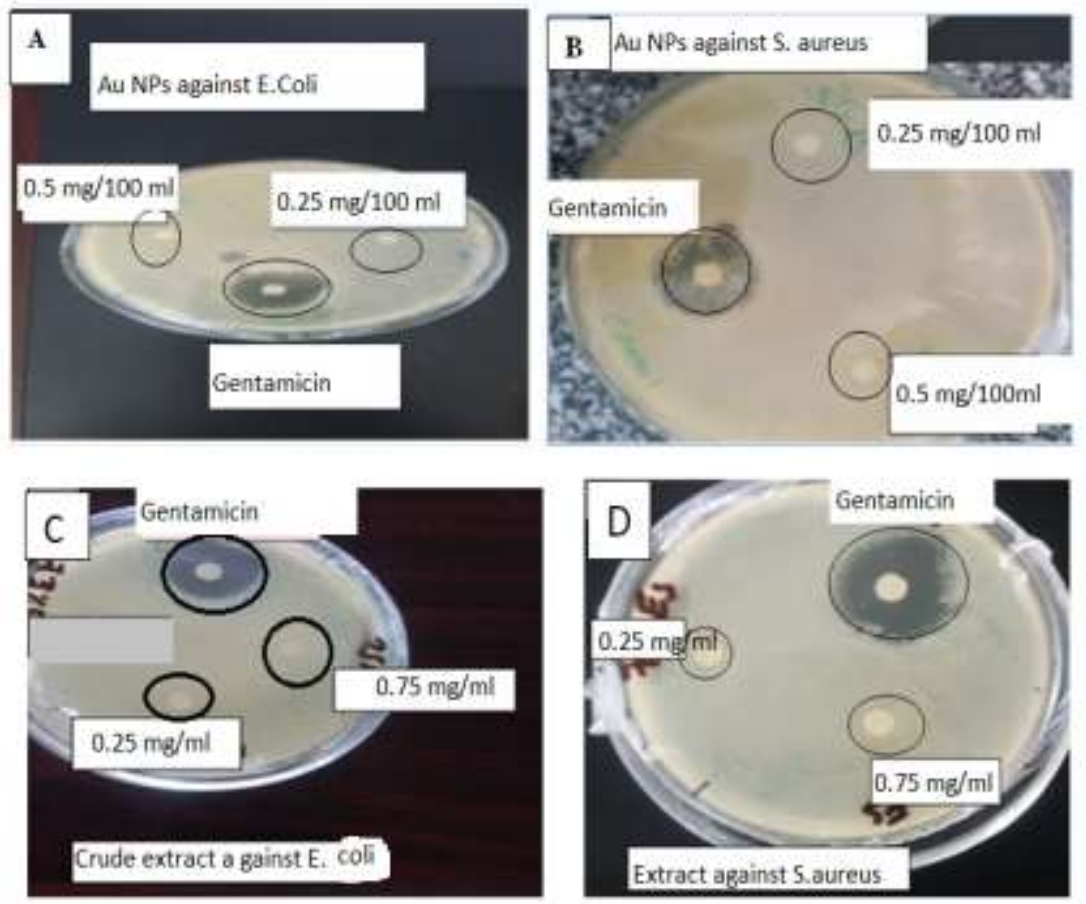

Figure 7. Antibacterial activities. A) Au NPs against E. coli, B) Au NPs against $S$. aureus, C) plant extracts against $E$. coil, D) Plant extract against $S$. aureus in refence to gentamicin.

The protonated form of bromothymol blue absorbs at $427 \mathrm{~nm}$ and deprotonated at $602 \mathrm{~nm}$. Similarly, the protonated methyl red molecules absorb strongly around $430 \mathrm{~nm}$ and de-protonated $540 \mathrm{~nm}$ (Nakkala et al., 2016). During the experiment, a measured quantity of Au NPs was added to methyl red and bromothyamol blue solution and the mixtures were digested for $1 \mathrm{~h}$. During digestion, $2 \mathrm{~mL}$ of aliquots (from both solutions) were taken every $15 \mathrm{~min}$ and scanned from 200 to $800 \mathrm{~nm}$. As the contact time increased, the absorption strengths of solutions decreased for both bromothyamol blue (Figure 8) and methyl red (not seen) while the absorbance of the control solution was kept almost constant. The absorbance intensities decreased as the contact time increased, confirming the degradation of dyes. The present result was consistent with previous experiments which were reported on the effective catalytic activity of $\mathrm{Au}$ NPs for the degradation of different toxic organic dyes including crystal violet, methyl red and methylene blue (Jyoti and Singh, 2016; Nakkala et al., 2016). 
- bromothyamol blue @0

- bromotyamol@15 min

- bromothyamol blue @30 min

$x$ bromothyamol blue @45 min

n-bromotyamolblue@1h

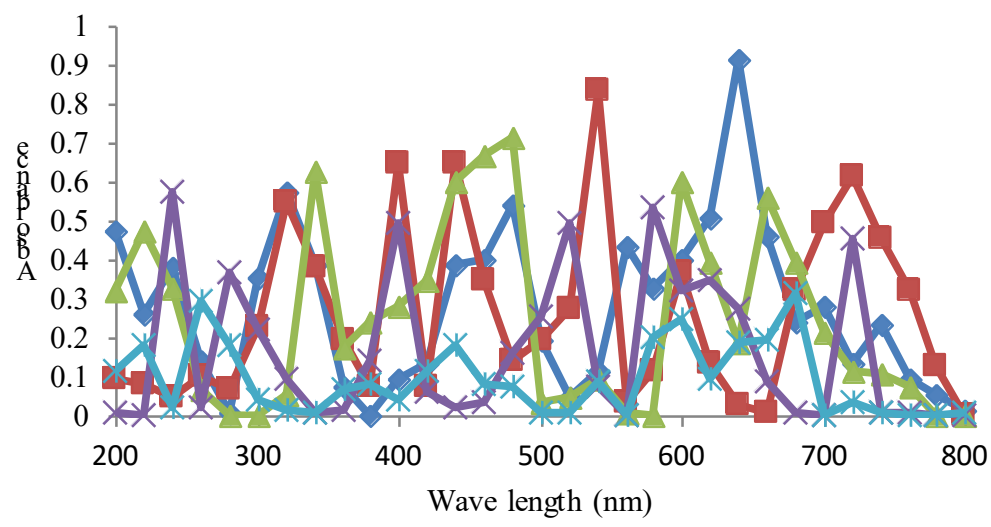

Figure 8. Catalytic activity of Au NPs for degradation of bromothyamol blue.

\section{Antioxidant activity of $\mathrm{Au}$ NPs}

DPPH radical is a well-known free radical which is used to study the antioxidant activities of compounds either by accepting electrons or protons during which the color of DPPH radical changes due to the formation of hydrazine molecules (Kumar et al., 2016). The antioxidant activities of the newly synthesized Au NPs and the D. abyssinica leaf extracts were studied in comparison with ascorbic acid as reference. Au NPs showed a strong inhibition potential at all concentrations as compared to ascorbic acid and the plant extract (Figure 9). The experimental result was consistent with Kumar et al. (2016) and Velammal et al. (2016) who reported the effective antioxidant performance of $\mathrm{Au}$ NPs synthesized using different plant extracts. This free radical inhibition potential of the newly synthesized $\mathrm{Au}$ NPs may help to increase the shelf life of lipids but it needs further toxicity test experiments for practical applications. 


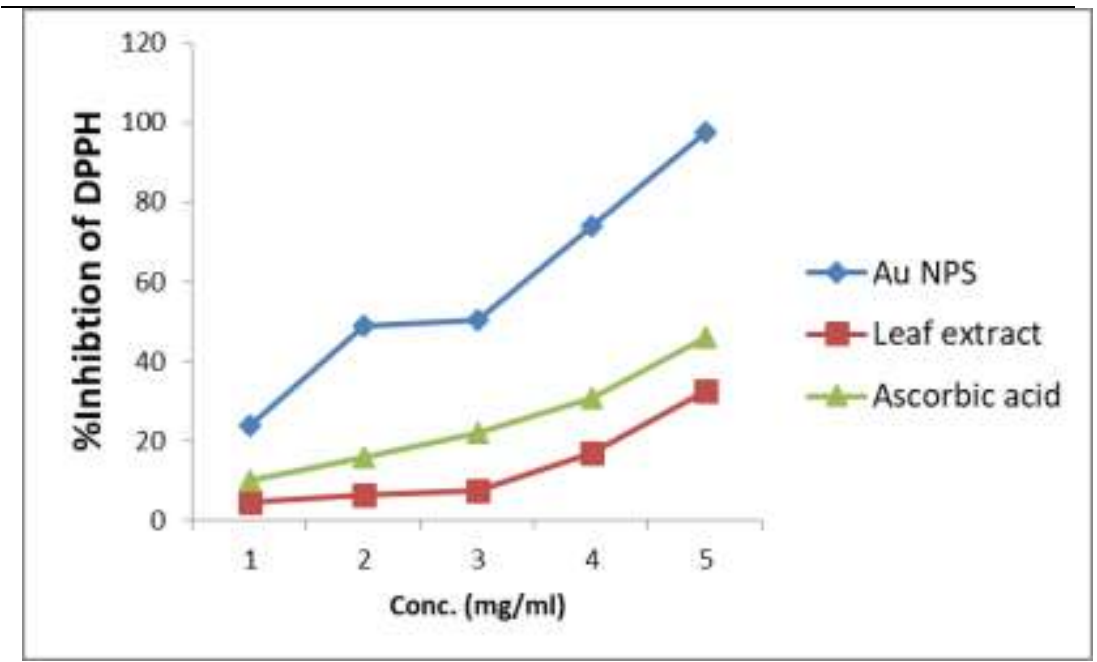

Figure 9. Antioxidant potential of synthesized Au NPs, leaf extract and ascorbic acid.

\section{Effect of polarity on reducing potential}

Based on the experimental results, compounds in ethyl acetate and aqueous fractions showed good reducing potential $\left(\mathrm{Au}^{3+}\right.$ to $\left.\mathrm{Au}\right)$ in terms of both size and concentration. The synthesized $\mathrm{Au}$ NPs from aqueous fraction was relatively better than ethyl acetate fraction but both the aqueous fraction and ethyl acetate fractions showed reduction efficiency than hexane fraction. The size of the Au NPs synthesized using aqueous fraction was comparable with the Au NPs synthesized from the crude extract but still the crude extract was more efficient (Table 3). The good reducing performance of the aqueous fraction could be suggested by the existence of highly polar molecules as water is highly polar solvent as compared to ethyl acetate and hexane. Highly polar molecules ionize easily and react with metal ions to reduce it and also chelate and stabilize nanoparticles. This study tips out that strongly polar molecules in D. abyssinica leaf extract have better reducing potential for the synthesis of Au NPs as compared to less polar compounds.

Table 3 Size of Au NPs synthesised using ethyl acetate, hexane and aqueous fractions and crude extract.

\begin{tabular}{lc}
\hline Reducing agents (fractions) & Average size Au NPs (d, nm) \\
\hline Crude extract & $63: 13: 00$ \\
Aqueous fraction & 68.45 \\
Ethyl acetate & 104.75 \\
Hexane & 215.43 \\
\hline
\end{tabular}




\section{CONCLUSION}

This work was designed to synthesis Au NPs using D. abyssinica leaf extract as reducing and stabilizing agent. Evaluation of the composition of the extract was done to study the nature of compounds and the test result confirmed the presence of tannins, phenolics, steroids, terpenes and saponins. $\mathrm{HAuCl}_{4}$ was successfully synthesized in the laboratory from metal gold and hydrochloric acid using a predesigned procedure. The Au NPs are synthesized by digesting a mixture of extracts of $D$. abyssinica leaves and $\mathrm{HAuCl}_{4}$ at $45^{\circ} \mathrm{C}$ for $1 \mathrm{~h}$. The size of Au NPs was modulated by varying the concentration of the plant extract and $\mathrm{HAuCl}_{4}$ in terms of volume ratio. The smallest average particle size was obtained to be $63.13 \mathrm{~nm}$ at the volume ratio $1: 1$ of reactants $\left(\right.$ D. abyssinica leaf $(1 \mathrm{mg} / \mathrm{mL})$ and $\left.2 \mathrm{mM} \mathrm{HAuCl}_{4}\right)$. The SEM image of the synthesized $\mathrm{Au}$ NPs showed mixed shapes of predominantly irregular with cylindrical rods with a characteristic crystalline structure of gold. The synthesized Au NPS showed excellent free radical inhibition potential as compared to the plant extract. Au NPS also showed much better activity than ascorbic acid which is a known antioxidant compound. The catalytic activity of the synthesized Au NPs on degradation of bromothymol blue and methyl red is efficient for the decomposition of both organic compounds. However, Au NPs did not show antibacterial activity on both gram negative (E. coil) and gram positive (S. aureus) which might be justified by the nature of the capping molecules from the plant extract or/and the size as well as the shape of the new nanoparticles. The nanoparticles synthesized in such environmentally friendly method might get its future application in industrial waste water treatment and for cancer therapy in medical institutes as well as for preservatives in food industries to increase the shelf life of lipids.

\section{REFERENCES}

Aljabali, A., Akkam, Y., Zoubi, M.S.A., Batayneh, K., Al-Trad, B., Alrob, O.A., Alkilany, A., Benamara, M and Evans, D. (2018). Synthesis of gold nanoparticles using leaf extract of Ziziphus zizyphus and their antimicrobial activity. Nanomaterials 8(3): 174. doi:10.3390/nano8030174

Anigol, L.B., Charantimath, J.S and Gurubasavaraj, P.M. (2017). Effect of concentration and $\mathrm{pH}$ on the size of silver nanoparticles synthesized by green chemistry. Organic and Medicinal Chemistry International Journal 3(5): ID.555622 doi:10.19080/OMCIJ.2017.03.555622.

Belay Taddese, Getachew Terefe., Nigatu Kebede and Workineh Shibeshi (2015). In vivo anti-trypanosomal activity of dichloromethane and methanol crude leaf extracts of Dovyalis abyssinica (Salicaceae) against Trypanosoma congolense. 
BMC Complementary Medicine and Therapies 15: 278. doi: 10.1186/s12906-0150809-y

Biao, L., Tan, S., Meng, Q., Gao, J., Zhang, X., Liu, Z and Fu, Y. (2018). Green synthesis, characterization and application of proanthocyanidins-functionalized gold nanoparticles. Nanomaterials 8(53). doi:10.3390/nano8010053

Chandran, P., Riviere, J.E and Monteiro-Riviere, N.A. (2017). Surface chemistry of gold nanoparticles determine the biocorona composition impacting cellular uptake, toxicity and gene expression profiles in human endothelial cells. Nanotoxicology 11(4): 507-519. doi: 10.1080/17435390.2017.1314036.

Dudhane, A.A., Waghmode, S.R., Dama, L.B., Mhaindarkar, V.P., Sonawane, A and Katariya, S. (2019). Synthesis and characterization of gold nanoparticles using plant extract of Terminalia arjuna with antibacterial activity. International Journal of Nanoscience and Nanotechnology 15(2): 75-82.

Francis, S., Joseph, S., Koshy, E.P and Mathew, B. (2017). Green synthesis and characterization of gold and silver nanoparticles using Mussaenda glabrata leaf extract and their environmental applications to dye degradation. Environmental Science and Pollution Research 24(21): 17347-17357. doi: 10.1007/s11356-0179329-2.

Francis, S., Koshy, E.P and Mathew, B. (2018). Green synthesis of Stereospermum suaveolens capped silver and gold nanoparticles and assessment of their innate antioxidant, antimicrobial and antiproliferative activities. Bioprocess and Biosystems Engineering 41(7): 939-951. doi: 10.1007/s00449018-1925-0.

Francis, S., Nair, K.M., Paul, N., Koshy, E.P and Mathew, B. (2019). Green synthesized metal nanoparticles as a selective inhibitor of human osteosarcoma and pathogenic microorganisms. Materials Today Chemistry 13: 128-138. doi.org/10.1016/j.mtchem.2019.04.013.

Gandhi, A.D., Murugan, K., Umamahesh, K., Babujanarthanam, R., Kavitha, P and Selvi, A. (2019). Lichen Parmelia sulcata mediated synthesis of gold nanoparticles: An eco-friendly tool against Anopheles stephensi and Aedes aegypti. Environmental Science and Pollution Research 26(23): 23886-23898. doi: 10.1007/s11356-019-05726-6.

Jyoti, K and Singh, A. (2016). Green synthesis of nanostructured silver particles and their catalytic application in dye degradation. Journal of Genetic Engineering and Biotechnology 14: 311-317. doi.org/10.1016/j.jgeb.2016.09.005.

Kato, Y., Yoshimura, E and Suzuki, M. (2019). Synthesis of gold nanoparticles by extracellular components of Lactobacillus casei. Chemistry Select 4: 73317337. doi: 10.1002/slct.201901046.

Khan, S., Bakht, J and Syed, F. (2018). Green synthesis of gold nanoparticles using Acer pentapomicum leaves extract its characterization, antibacterial, antifungal and antioxidant bioassay. Digest Journal of Nanomaterials and Biostructures 13(2): 579-589. Corpus ID: 203651124

King, S.R., Massicot, J and McDonagh, A.M. (2015). A straightforward route to tetrachloroauric acid from gold metal and molecular chlorine for nanoparticle synthesis. Metals 5(3): 1454-461. doi.org/10.3390/met5031454.

Kumar, B., Smita, K., Vizuete, K.S and Cumbal, L. (2016) aqueous phase lavender leaf mediated green synthesis of gold nanoparticles and evaluation of its 
antioxidant activity. Biology and Medicine 8: 3 . doi: 10.4172/09748369.1000290.

Malathi, R., Kaviyarasan, D and Chandrasekar, S. (2018). Preliminary phytochemical analysis of Jjusticia adhatoda leaves extract using different solvents. International Journal of Pharmaceutics \& Drug Analysis 6: 186-190. http://ijpda.com.

Mata, R., Bhaskaran, A and Sadras, S.R. (2016). Green-synthesized gold nanoparticles from Plumeria alba flower extract to augment catalytic degradation of organic dyes and inhibit bacterial growth. Particuology 24: 78-86. doi.org/10.1016/j.partic.2014.12.014.

Nakkala, J.R., Mata, R and Sadras, S.R. (2016). The antioxidant and catalytic activities of green synthesized gold nanoparticles from Piper longum fruit extract. Process Safety and Environmental Protection 100: 288-294. doi.org/10.1016/j.psep.2016.02.007.

Patil, M.P., Seo, Y.B., Lim, H.K and Kim, G. (2019). Biofabrication of gold nanoparticles using Agrimonia pilosa extract and their antioxidant and cytotoxic activity. Green Chemistry Letters and Reviews 12: 208-216. doi: $10.1080 / 17518253.2019 .1623927$

Shirin, R., King, J.M and Andrew, M.M. (2015). A straightforward route to tetrachloroauric acid from gold metal and molecular chlorine for nanoparticle synthesis. Metals 5(3): 1454-461. doi:10.3390/met5031454.

Singh, B and Sharma, A. (2015). Plant terpenes: defense responses, phylogenetic analysis, regulation and clinical applications. 3 Biotech 5(2): 129-151. doi: 10.1007/s13205-014-0220-2

Singh, P., Kim, Y.J., Wang, C., Mathiyalagan, R and Yang, D.C. (2016). The development of a green approach for the biosynthesis of silver and gold nanoparticles by using Panax ginseng root extract, and their biological applications. Artificial Cells, Nanomedicine, and Biotechnology 44: 1150-1157. doi: 10.3109/21691401.2015.1011809

Srinath, B.S., Namratha, K and Byrappa, K. (2017). Eco-friendly synthesis of gold nanoparticles by gold mine bacteria Brevibacillus formosus and their antibacterial and biocompatible studies. Iosr Journal of Pharmacy 7(8): 53-60. Corpus ID: 212555380

Velammal, S.P., Devi, T.A and Amaladhas, T.P. (2016). Antioxidant, antimicrobial and cytotoxic activities of silver and gold nanoparticles synthesized using Plumbago zeylanica bark. Journal of Nanostructure in Chemistry 6(3): 247-260. doi:10.1007/s40097-016-0198-x.

Vijayan, R., Joseph, S and Mathew, B. (2018). Anticancer, antimicrobial, antioxidant, and catalytic activities of green-synthesized silver and gold nanoparticles using Bauhinia purpurea leaf extract. Bioprocess Biosystems and Engineering 42(2): 305-319. doi:10.1007/s00449-018-2035-8.

Vijayan, R., Joseph, S and Mathew, B. (2017). Green synthesis, characterization and applications of noble metal nanoparticles using Myxopyrum serratulum A. W. Hill leaf extract. Bio Nano Science 8(1): 105-117. doi:10.1007/s12668-017-0433-z. 